\title{
Retraction Note to: Prevalence of ixodid ticks on cattle and sheep northeast of Iran
}

\author{
Mehdi Aghamohammad Hassan ${ }^{1}$ - Afshin Raoofi ${ }^{1} \cdot$ Arman Hosseini $^{1}$ • \\ Mohammad Reza Mehrara ${ }^{2}$. Fatemeh Amininajafi $^{3}$
}

Published online: 4 November 2016

(C) Indian Society for Parasitology 2016

\section{Retraction Note to: J Parasit Dis (July-Sept 2016) 40(3):772-773 \\ DOI 10.1007/s12639-014-0576-6}

This article has been retracted at the request of the Editorin-Chief, The Indian Society for Parasitology (ISP) and the Publisher per the Committee on Publication Ethics guidelines. There is strong reason to believe that the peer review process was compromised and the authors have plagiarized parts from the following article:
Mohammad Mirzaei Dehaghi, Saeid Fathi, Ehsan Norouzi Asl, Hojat Asgary Nezhad, Prevalence of ixodid ticks on cattle and sheep southeast of Iran. Tropical Animal Health and Production. 2011; 43:2 459-461

DOI: $10.1007 / \mathrm{s} 11250-010-9715-y$

As such, the validity of the content of this article cannot be verified.

The online version of the original article can be found under doi:10.1007/s12639-014-0576-6.

Mehdi Aghamohammad Hassan

aghamh@ut.ac.ir

1 Department of Clinical Science, Faculty of Veterinary

Medicine, Tehran University, Tehran, Iran

2 Doctor of Veterinary Medicine, Tehran, Iran

3 Department of Pathology, Faculty of Veterinary Medicine, Tehran University, Tehran, Iran 